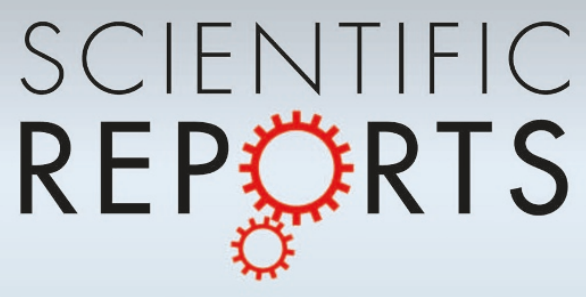

OPEN

SUBJECT AREAS:

HETEROGENEOUS

CATALYSIS

MATERIALS FOR ENERGY AND

CATALYSIS

RENEWABLE ENERGY

Received

29 November 2013

Accepted

14 January 2014

Published

7 February 2014

Correspondence and requests for materials should be addressed to W.P.D. (Dingwp@nju. edu.cn)

* These authors contributed equally to this work.

\section{High performance catalytic distillation using CNTs-based holistic catalyst for production of high quality biodiesel}

\author{
Dongdong Zhang '*, Dali Wei' ${ }^{*}$, Qi Li', Xin Ge', Xuefeng Guo' , Zaiku Xie² \& Weiping Ding'
}

'Key Lab of Mesoscopic Chemistry, the School of Chemistry and Chemical Engineering, Nanjing University, Nanjing 210093, China, ${ }^{2}$ Shanghai Research Institute of Petrochemical Technology, Shanghai 201208, China.

For production of biodiesel from bio oils by heterogeneous catalysis, high performance catalysts of transesterification and the further utilization of glycerol have been the two points of research. The process seemed easy, however, has never been well established. Here we report a novel design of catalytic distillation using hierachically integrated CNTs-based holistic catalyst to figure out the two points in one process, which shows high performance both for the conversion of bio oils to biodiesel and, unexpectedly, for the conversion of glycerol to more valuable chemicals at the same time. The method, with integration of nano, meso to macro reactor, has overwhelming advantages over common technologies using liquid acids or bases to catalyze the reactions, which suffer from the high cost of separation and unsolved utilization of glycerol.

iodiesel made from bio oils, as a kind of high quality fuel, has drawn much more research attentions in recent years ${ }^{1-3}$. High performance transesterification process and the treatment of main by-product glycerol have been the two points of research. Commonly, liquid acids or bases are used to catalyze transesterification and esterification reactions $s^{4-6}$, which suffer from the largely excess quantity of methanol needed to remove equilibration limit on conversion and the high cost of separation ${ }^{7-9}$. And the utilization of glycerol, as main by-product, is still a question. Some heterogeneous catalysts used for the reaction have been developed, including $\mathrm{KOH} / \mathrm{Al}_{2} \mathrm{O}_{3}{ }^{10}, \mathrm{Al}_{2} \mathrm{O}_{3} / \mathrm{SnO}^{11}, \mathrm{Li} / \mathrm{MgO}^{12}$, Amberlyst- $15^{13}$, Nafion ${ }^{14}$, and zeolites ${ }^{15}$. These processes using solid catalysts, however, demand rigorous conditions, such as free of dissociative fatty acids ${ }^{16-18}$. And recently, carbon-based solid acids have been reported promising to catalyze reactions of esterification or transesterification to produce biodiesel ${ }^{19-25}$. Considering the big advantages of catalytic distillation as intensified processes for the highly efficient couple of reactions and separation, some investigators have reported on the implementation of a reactive distillation to biodiesel production with acidic resin Amberlyst- 15 or sodium hydroxide as catalysts ${ }^{26,27}$. The general performances of these catalysts, however, are still much inferior to the demand.

In this report, a continuous catalytic distillation process using shaped holistic catalysts with CNTs grown on stainless steel wire mesh has been developed and shown high performance for transesterification of bio oils with methanol and surprisingly also for the synchronous conversion of glycerol to high valued products. The catalytic distillation apparatus for the research purpose is schematically shown as Fig. 1. Firstly, the carbon nanotubes were tightly grown on the steel wires of the mesh and then the mesh was shaped as Raschig rings (diameter: $2 \mathrm{~mm}$, length $2 \mathrm{~mm}$ ). After sulfonation, the Raschig rings were loaded in a catalytic distillation column (height: $200 \mathrm{~mm}$, diameter: $20 \mathrm{~mm}$ ). The transesterification of bio oils with methanol was carried out using the distillation column at $493 \mathrm{~K}$ in high efficiency, due to the simultaneous separation removing the limitation of chemical equilibrium. Unexpectedly, the glycerol, as the by product of the reaction in common processes, was found simultaneously to convert to a series of higher valuable compounds over the catalytic column, which would extremely promoted the performance of the process scientifically and economically.

\section{Results}

Preparation of the holistic catalyst. Fig. 2a shows the photograph of the fresh stainless steel mesh with the wires in diameter of $200 \mu \mathrm{m}$. Before the CNTs' growth, the metallic cobalt nanoparticles, synthesized according to ref. 28 , have been coated to the wires as catalysts for CNTs rooted on the wires (inset). Fig. 2b depicts the stainless steel mesh with thickly grown CNTs and the Rashig rings made from the stainless steel mesh (inset). Fig. $2 \mathrm{c}$ shows the compact and orderly CNTs' array on the wires with the length of CNTs about $\sim 30 \mu \mathrm{m}$. The carbon nanotubes are in good shape of one dimensional morphology and the metallic particles of catalyst, cobalt and iron, are evidently 


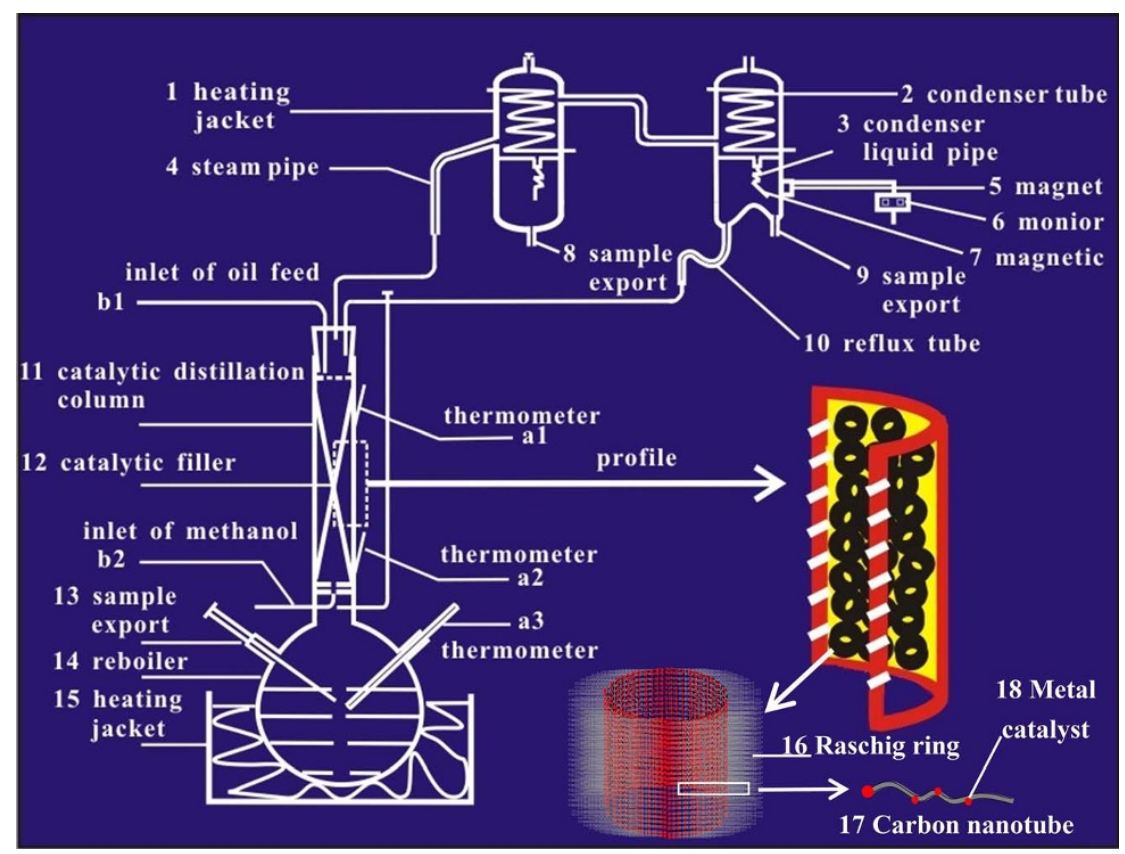

Figure 1 The schematic show of the catalytic distillation apparatus for the transesterification of bio oils and the synchronous conversion of glycerol to high valuable products.

clued or embedded in the carbon nanotube along its length (Fig. 2d) ${ }^{29}$. The metal nanoparticles would be also included in catalytic reactions.

The CNTs on the Rashig rings are sulfurated with $\mathrm{Na}_{2} \mathrm{~S}_{x}$ and oxidized by hydrogen peroxide to sulfonic acid. After the chemical treatment, the carbon nanotubes arrays on the wires are still in similar to the original steel mesh (Figs. 3a and 3b). The Raman spectra of

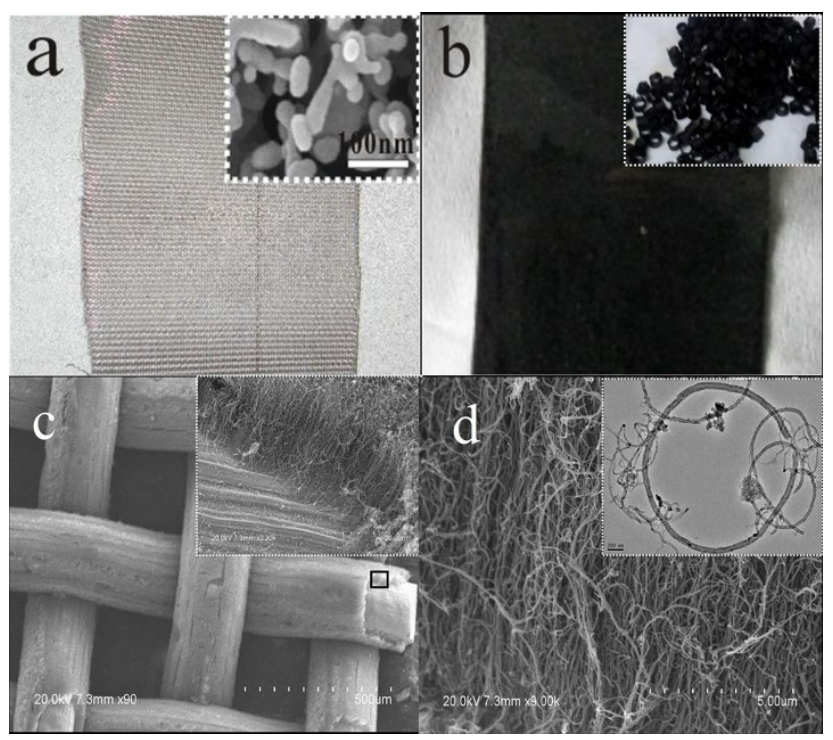

Figure $2 \mid$ The stainless steel meshes and the cobalt nanoparticles coated onto the meshes (SEM, inset); (b) The stainless steel meshes after CNTs growth and the Raschig rings (inset); (c) SEM image of stainless steel mesh coated with pristine CNTs and the inset shows the morphology of the CNTs array; (d) Enlarged SEM image of the CNTs array and the inset shows TEM images of CNTs taken from the stainless steel mesh and catalytic particles used for CNTs growth is evident. The cobalt nanoparticles synthesized in advance was coated to the wire mesh before the CNTs' growth and the ferrocene containing benzene was used as carbon source for the CNTs' growth. original and chemically treated CNTs are shown in Fig. 3c. The bands at $\sim 1356$ and $\sim 1585 \mathrm{~cm}^{-1}$ are the characteristic D-band and Gband of graphite carbon, respectively. The G-band is attributed to the tangential mode of the graphitic structure, while D-band corresponds to the defects or limited dimensions of CNT crystal structure $^{30}$. The intensity of the G-band is stronger than the D-band, indicating the high degree of graphitization. For the sample of CNT-SH, new peaks at 472,673 and $2727 \mathrm{~cm}^{-1}$ are observed. The peak at $472 \mathrm{~cm}^{-1}$ is associated with bend vibrations of $\mathrm{S}=\mathrm{C}-\mathrm{S}$ bonds ${ }^{31}$, the $673 \mathrm{~cm}^{-1}$ peak is related to stretch vibrations of C-S bonds $\mathrm{s}^{9,31,32}$, while the $2727 \mathrm{~cm}^{-1}$ band is stretch vibrations of S-H bonds ${ }^{33}$. For the sample after oxidation with $\mathrm{CNT}-\mathrm{SO}_{3} \mathrm{H}$ groups, the peak at $2708 \mathrm{~cm}^{-1}$ from stretching vibrations of $\mathrm{O}-\mathrm{H}$ bonds in sulfonic group arises ${ }^{34}$.

Figure 3d showed XPS spectra of the sulfonated CNTs-based structured catalyst. Three peaks, respectively positioned at $284.5,286.3$, and $288.7 \mathrm{eV}$, are observed in the $\mathrm{C} 1 \mathrm{~s}$ region. The peak centered at $284.5 \mathrm{eV}$ can be attributed to the $\mathrm{sp}^{2}$ - hybridized graphite carbon. The peak at $286.3 \mathrm{eV}$ is contributed from carbon atoms in the C-O- species ${ }^{35}$. The peak at $288.7 \mathrm{eV}$ is associated with the carbon atoms in C-S species ${ }^{36}$. The O1s binding energy can be deconvoluted into two peaks at 531.5 and $532.1 \mathrm{eV}$, which are assigned as oxygen atoms in $\mathrm{S}-\mathrm{OH}$ and $\mathrm{C}-\mathrm{OH}$, respectively. In the region of S2p, two peaks appeared at 168.5 and $169.7 \mathrm{eV}$ are detected, which are assigned to the $-\mathrm{SO}_{3} \mathrm{H}$ groups in the sample ${ }^{37}$. The chemical composition of the holistic catalyst analyzed by EDX equipped to the scanned electron microscopy is listed in Table 1 and the effective protonic acid density attached to the CNTs measured by titration is also listed in table 1 . The results confirm the high content of sulfur in the catalyst. After oxidation treatment, the oxygen content increases remarkably and implies the existence of groups of $-\mathrm{COOH}$ and $-\mathrm{OH}$, besides the groups of $-\mathrm{SO}_{3} \mathrm{H}$. The acid density of $2.54 \mathrm{mmol} \cdot \mathrm{g}^{-1}$ is a medium-high value among the carbonbased solid acids documented.

Catalytic distillation process for bio oil conversion. The Rashig rings are loaded as fillers into a catalytic distillation column, $20 \mathrm{~mm}$ in diameter and $200 \mathrm{~mm}$ in height. The total amount of CNTs grown on the Rashig rings is $\sim 2.1 \mathrm{~g}$ with total surface area about $450 \mathrm{~m}^{2}$. During catalytic operation, the reactive mixtures of 


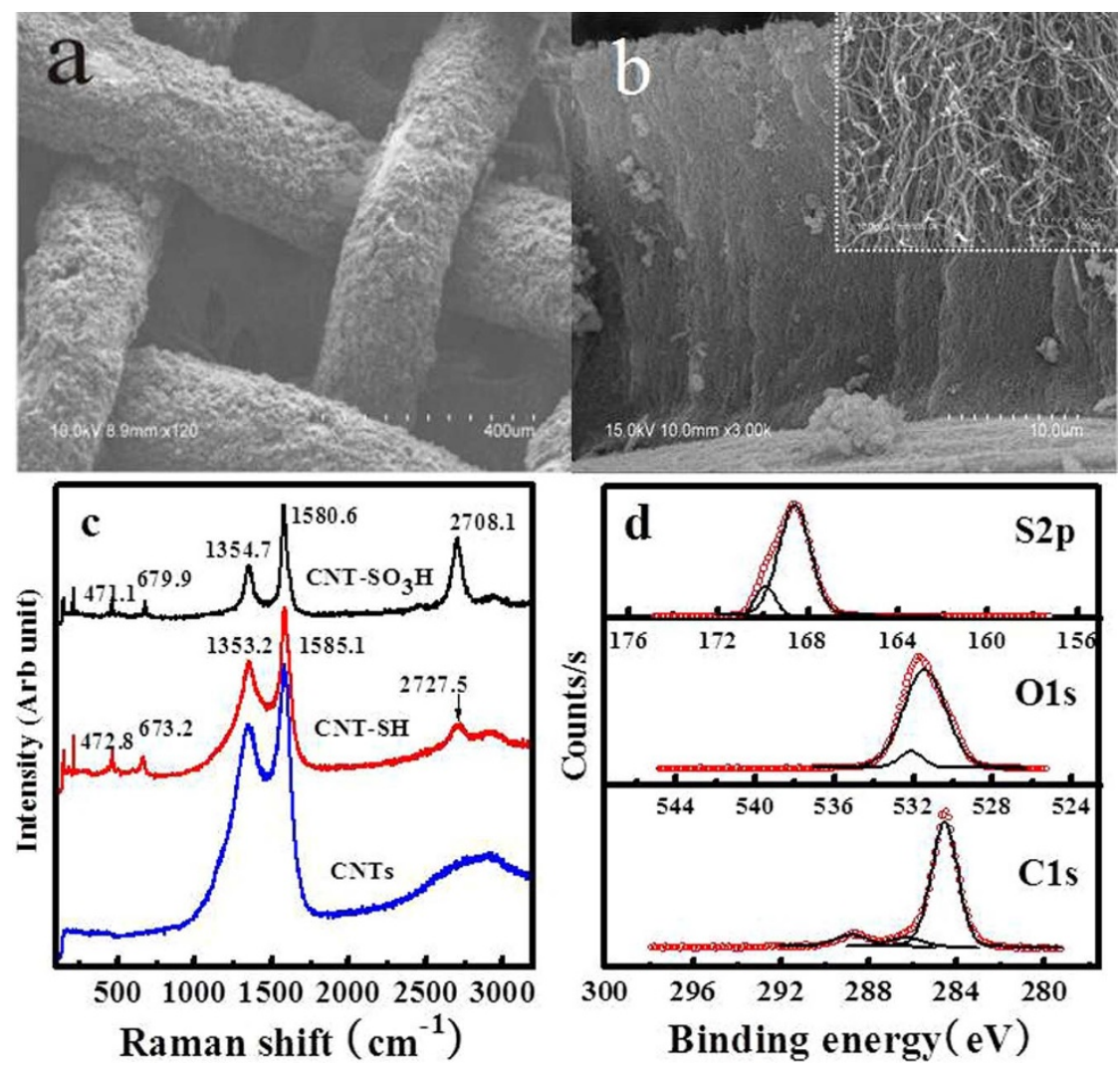

Figure 3 SEM images of stainless steel mesh coated with $\mathrm{CNT}_{-} \mathrm{SO}_{3} \mathrm{H}$; (b) Enlarged SEM images of the CNTs arrays; (c) Raman spectra of the CNTs at different stage; (d) C1s, O1s and S2p XPS spectra of the $\mathrm{CNT}-\mathrm{SO}_{3} \mathrm{H}$ after sulfonation.

liquids and gases, at different positions of the catalytic column, are taken out for analysis. Figs. $4 \mathrm{a}$ and $4 \mathrm{~b}$ depict respectively the compositions of gas phase and liquid phase at different position along the catalytic column. The concentration of FAME increases with the positions from top to bottom of the catalytic column. Unexpectedly, glycerol, as the main by product of transesterification, is not detected along the catalytic column. The byproducts detected include glyceric acid, glyceraldehyde, 1,1-Dimethoxyhexane, acrolein dimethyl acetal and some short chain alkanes. The quantitative results of analysis on the products taken at the export 8 and the reboiler are listed in Table 2. It is suggested that the glycerol producing by transesterification reaction can further transform into glyceric acid, glyceraldehyde, 1,1-Dimethoxyhexane and acrolein dimethyl acetal by the catalysis on the column.

Noteworthy that the performance of the process is much stable in $100 \mathrm{~h}$ of operation, and the morphology of the catalyst appears unchanged after $100 \mathrm{~h}$ reaction (Figs. 4c). Comparing with some

Table 1 | Chemical composition of the holistic catalyst on steel mesh analyzed by EDX and the acid density measured by chemical titration using $\mathrm{NaOH}$

\begin{tabular}{|c|c|c|c|c|c|}
\hline \multirow[b]{2}{*}{ Element } & \multicolumn{2}{|c|}{ CNTs-SH } & \multicolumn{2}{|c|}{$\mathrm{CNTs}-\mathrm{SO}_{3} \mathrm{H}$} & \multirow[b]{2}{*}{$\mathrm{H}_{2} \mathrm{SO}_{4}$} \\
\hline & Weight \% & Atomic \% & Weight \% & Atomic \% & \\
\hline$C$ & 90.80 & 95.1 & 63.3 & 72.0 & - \\
\hline 0 & 3.20 & 2.5 & 28.9 & 24.6 & \\
\hline S & 6.00 & 2.4 & 7.8 & 3.4 & \\
\hline $\begin{array}{l}\text { Acid density } \\
\left(\mathrm{mmol} \mathrm{g}^{-1}\right)\end{array}$ & & - & 2.541 & $1.98 * 1$ & 20.4 \\
\hline
\end{tabular}

*The figures in the parenthesis show the acid density measured by chemical titration after $100 \mathrm{~h}$ reaction. results documented on the transesterification of bio oil with methanol, which required a large excess methanol at common conditions $^{38-40}$, the current method possesses overwhelming advantages by intensifying the reaction with simultaneous separation and synchronous transformation of glycerol. The reaction network is elucidated as Fig. 5 and a mathematical model has been developed to describe the current catalytic distillation process for biodiesel production (supporting information and Figs. S1 and S2).

\section{Discussion}

In the catalytic column used in current investigation, multi factors are involved and contribute to the catalytic performance, such as the nanoparticles of cobalt and iron used for growth of carbon nanotubes on stainless steel meshes, the acid centers formed by sulfonation of CNTs and the interactions among them for synergistic effects. The acid centers contribute to the transesterification and dehydration of glycerol and the metallic centers loaded on or encapsulated in the carbon nanotubes contribute to the reactions of dehydrogenation and hydrogenation with methanol. Very recently, Beller et al have reported that the carbon buried metals, such as iron oxide or cobalt, are active for the hydrogenation of nitroarenes to anilines ${ }^{41,42}$. The sum of the factors, intensified by the effect of temporal separation of catalytic distillation, constitutes the high performance process for production of biodiesel and synchronous conversion of glycerol.

As the following development of nano research ${ }^{43}$, the thoughts of meso science are very applicable for catalysis research, which means a kind of complication and includes many more interactions among its nano constituents. The current work includes an integration of catalytic technology, in size from nano, meso to macro reactor and easy to scale up to industrial equipment, to meet the demand on the upgrade of practical industry processes with more efficiency, less emission and energy save. 

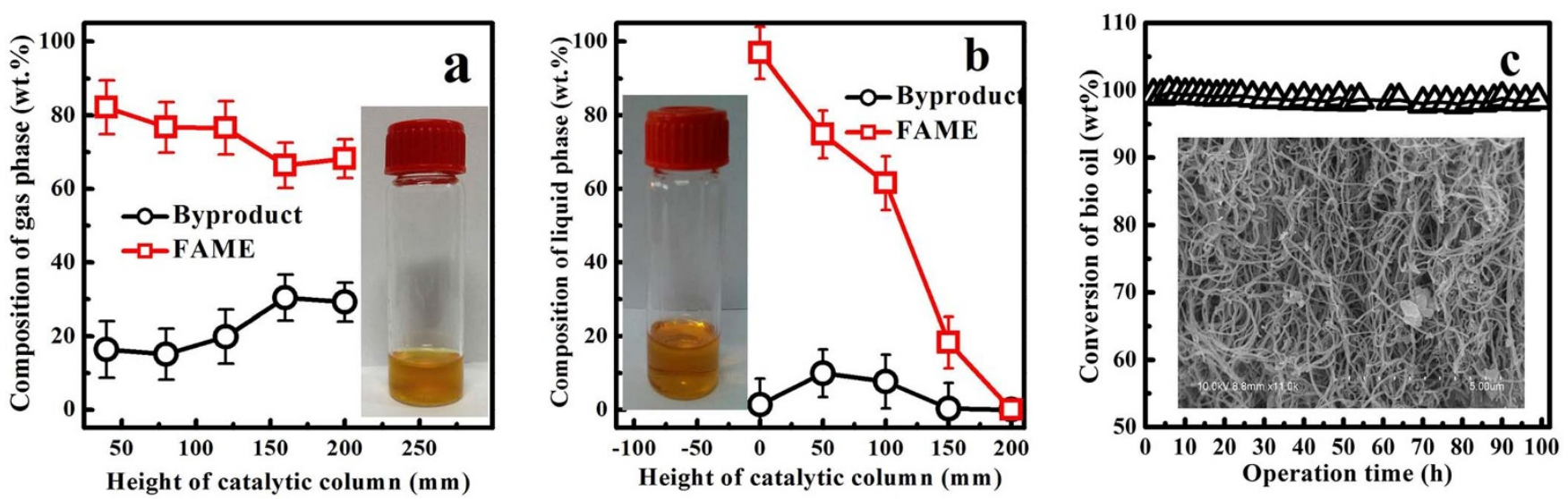

Figure $4 \mid$ (a)The composition of gas phase at the different height of the catalytic column (inset: the photograph of the products at the sample export 8.); (b) The composition of liquid phase at the different position of the catalytic column (inset: the photograph of the products in the reboiler 14.); (c) The variation of bio oil conversion with the operation time in $100 \mathrm{~h}$ and inset shows the SEM image of the CNTs on steel mesh after used for about $100 \mathrm{~h}$. (Temperatures: the catalytic column, $493 \mathrm{~K}$; inlet of oil feed (b1), $408 \mathrm{~K}$; inlet of methanol (b2), $388 \mathrm{~K}$; reboiler (14), $388 \mathrm{~K}$; condenser 1, $378 \mathrm{~K}$; condenser 2, fully cooled. Flow rate: oil (b1), $10.85 \times 10^{-3} \mathrm{~mol} \cdot \mathrm{min}^{-1}$; methanol (b2), $1.73 \times 10^{-3} \mathrm{~mol} \cdot \mathrm{min}^{-1}$.)

In conclusion, we have demonstrated a design for a catalytic distillation with improved efficiency and enhanced stability for biodiesel production, as well as synchronous conversion of glycerol to a series of high valuable chemicals in situ on the catalytic column of distillation, by well shaped assembling and stabilizing sulfonated carbon nanotubes on stainless steel meshes with cobalt and iron metal nanoparticles in scales from nano, meso to macro reactor. Considering the large quantity of industrial processes adaptive to catalytic distillation, the current integrative design could be built for a broad range of applications. Moreover, by judiciously choosing the further modification of the carbon nanotubes with catalytic functions, we foresee the creation of novel families of catalytic distillation technologies with high efficiency, low emission and energy save.

\section{Methods}

Pretreatment of the stainless steel meshes. $316 \mathrm{~L}$ stainless steel meshes with wires of $200 \mu \mathrm{m}$ in diameter were washed by ethanol to remove organic smears and etched in hydrochloric acid for $15 \mathrm{~min}$ at $333 \mathrm{~K}$. The treated meshes were then immersed into a sol containing metallic cobalt nanoparticles, which was prepared in advance according to the method similar to that reported in ref. 29 . The meshes attached by the cobalt nanoparticles were then dried in vacuum.

Growth of the CNTs. The stainless steel meshes coated with Co nanoparticles were loaded in a porcelain boat, which was placed in a horizontal quartz tubular furnace. The meshes were firstly heated to $873 \mathrm{~K}$ for $1 \mathrm{~h}$ in $10 \mathrm{vol} . \% \mathrm{H}_{2} /$ Ar flow to clean the surface for $2 \mathrm{~h}$. When the temperature was ramped to $973 \mathrm{~K}, 1 \mathrm{wt}$. \% ferrocene containing xylene or benzene (as carbon source) was injected continuously by a syringe and evaporated in the flow for CNTs growth ${ }^{30}$. The growth time was controlled as $1 \mathrm{~h}$ in the flowing 10 vol. $\% \mathrm{H}_{2} / \mathrm{Ar}$ at $973 \mathrm{~K}$.

Sulfonation. The stainless steel meshes with CNTs were put into $\mathrm{Na}_{2} \mathrm{~S}_{x}$ saturated solution at $358 \mathrm{~K}$ under stirring for $24 \mathrm{~h}$ for sulfuration of the CNTs as CNTs-SH. Thereafter, hydrogen perfoxide was used to oxidize the CNTs-SH to CNTs-SO ${ }_{3} \mathrm{H}$ at

Table 2 | The compositions of products at the column top (export 8) and the column bottom (reboiler)

\begin{tabular}{lcc} 
product & Top (wt. \%) & Bottom (wt. \%) \\
\hline FAME & 68.2 & 97.0 \\
Glyceraldehyde & 1.7 & 0.2 \\
Glycericacid & 4.3 & 0.3 \\
Acrolein dimethyl acetal & 4.5 & 0.4 \\
1, 1-Dimethoxyhexane & 9.3 & 0.5 \\
Linoleic acid monoester & - & 1.1 \\
Others & 12.0 & 0.6
\end{tabular}

*The excess methanol is refluxed to the b2 inlet. The product in reboiler is taken out directly without further treatment. The condensate at the export 8 is collected without further treatment. room temperature. Finally, the sample was thoroughly washed by ethanol and distilled water.

Catalytic column. The stainless steel meshes were tailored and shaped as Raschig rings to be loaded in a catalytic column of $20 \mathrm{~mm}$ of inner diameter and $200 \mathrm{~mm}$ in length, surrounded by a heating furnace. The apparatus for catalytic distillation is shown as Fig. 1.

Catalytic test. The bio oil and methanol as the feedstocks were individually injected at the inlets of $\mathrm{b} 1$ and $\mathrm{b} 2$, respectively, which were heated to different temperatures. The products were obtained at two places when the temperature of the catalytic column was set at $493 \mathrm{~K}$. The first stage of condenser was set at $383 \mathrm{~K}$ to recover a part of products from transesterification and the products from the simultaneous conversion of glycerol at the column. The second condenser was fully cooled to recover the methanol, which was fed back to the catalytic column. The reboiler was set at $383 \mathrm{~K}$ in order to gain the pure biodiesel from the column bottom. The process was operated continuously. The product samples were analyzed using GC-MS (thermo finnigan trace GC2000 DSQ) equipped with a DB-5MS column $(30 \mathrm{~m} \times 0.32 \mathrm{~mm} \times$ $0.25 \mu \mathrm{m})$.

Characterization. Laser Raman spectroscopy (Renishaw Iinvia) was used to characterize the carbon materials. Scanning electron microscope (SEM, LEO1530 VP instrument), transmission electron microscope (TEM, JEM-110) and high resolution transmission electron microscope (HRTEM, JEM-2100) were used to observe the morphologies of the catalysts and the CNTs. X-ray diffraction measurements (XRD) were performed on a Philips X'Pro X-ray diffractometer with $\mathrm{Cu} \mathrm{K} \alpha$ irradiation $(\lambda=$ $0.15418 \mathrm{~nm}$ ). The X-ray source was operated at $40 \mathrm{kV}$ and $40 \mathrm{~mA}$. XPS spectra were obtained under ultra high vacuum $\left(<10^{-6} \mathrm{~Pa}\right)$ on UlVAC-PHI 5000 Versa Probe with an $\mathrm{Al}$ anode $(\mathrm{Al} \mathrm{K \alpha}=1486.6 \mathrm{eV})$. All binding energies were calibrated using the
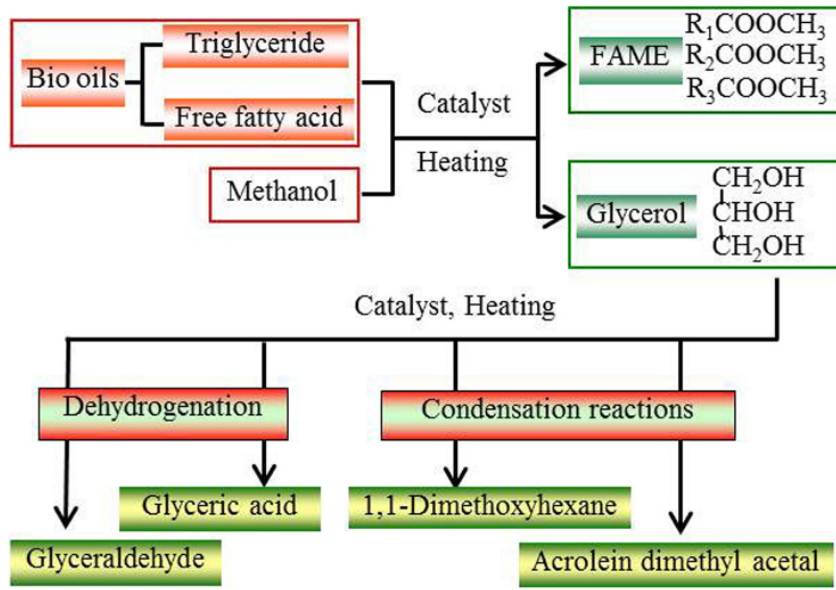

Figure $5 \mid$ The reaction network of transesterification of bio oils with methanol and the in situ transformation of the glycerol. 
carbon $1 \mathrm{~s}$ as a reference. The sulfur contents of the sulfonated carbon catalysts were determined by elemental analysis using EDX. The acid density of the obtained meshes with CNTs was measured by chemical titration using diluted solution of sodium hydroxide.

1. Kiss, A. A. \& Bildea, C. S. A review of biodiesel production by integrated reactive separation technologies. J. Chem. Technol. Biotechnol 87, 861-879 (2012).

2. Nguyen, N. \& Demirel, Y. Using thermally coupled reactive distillation columns in biodiesel production. Energy 36, 4838-4847 (2011).

3. Kiss, A. A., Dimian, A. C. \& Rothenberg, G. Biodiesel by catalytic reactive distillation powered by metal oxides. Energy Fuels 22, 598-604 (2008).

4. Lotero, E. et al. Synthesis of biodiesel via acid catalysis. Ind. Eng. Chem. Res. 44, 5353-5363 (2005)

5. Goff, M. J., Bauer, N. S., Lopes, S., Sutterlin, W. R. \& Suppes, G. J. Acid-catalyzed alcoholysis of soy- bean oil. J. Am. Oil. Chem. Soc. 81, 415-420 (2004).

6. Narvaez, P. C., Rincon, S. M. \& Sanchez, F. J. Kinetics of palm oil methanolysis. J. Am. Oil Chem. Soc. 84, 971-977 (2007).

7. Baddour, C. E. et al. A simple thermal CVD method for carbon nanotube synthesis on stainless steel 304 without the addition of an external catalyst. Carbon $\mathbf{4 7}$, 313-318 (2009).

8. Konya, Z. et al. Large scale production of short functionalized carbon nanotubes. Chem. Phys. Lett. 360, 429-435 (2002).

9. Lim, J. K. et al. Selective thiolation of single-walled carbon nanotubes. Synth. Met. 139, 521-527 (2003).

10. Noiroj, K., Intarapong, P., Luengnaruemitchai, A. \& Jai-In, S. A comparative study of $\mathrm{KOH} / \mathrm{Al}_{2} \mathrm{O}_{3}$ and $\mathrm{KOH} / \mathrm{NaY}$ catalysts for biodiesel production via transesterification from palm oil. Renew. Energy 34, 1145-1150 (2009)

11. Macedo, C. C. S. et al. New heterogeneous metal-oxides based catalyst for vegetable oil trans-esterification. J. Braz. Chem. Soc. 17, 1291-1296 (2006).

12. Xie, W. L. \& Li, H. T. Alumina-supported potassium iodide as a heterogeneous catalyst for biodiesel production from soybean oil. J. Mol. Catal. A Chem. 255, 1-9 (2006)

13. Talukder, M. M. R. et al. Comparison of novozym 435 and amberlyst 15 as heterogeneous catalyst for production of biodiesel from palm fatty acid distillate. Energy Fuels 23, 1-4 (2009).

14. Ngaosuwan, K., Lotero, E., Suwannakarn, K., Goodwin, J. G. \& Praserthdam, P. Hydrolysis of triglycerides using solid acid catalysts. Ind. Eng. Chem. Res. $\mathbf{4 8}$, 4757-4767 (2009).

15. Ramos, M. J., Casas, A., Rodriguez, L., Romero, R. \& Perez, A. Transesterification of sunflower oil over zeolites using different metal loading: A case of leaching and agglomeration studies. Appl. Catal. A Gen. 346, 79-85 (2008).

16. Shu, Q. et al. Synthesis of biodiesel from waste vegetable oil with large amounts of free fatty acids using a carbon-based solid acid catalyst. Appl. Energy 87, 2589-2596 (2010)

17. Kastner, J. R. et al. Catalytic esterification of fatty acids using solid acid catalysts generated from biochar and activated carbon. Catal. Today 190, 122-132 (2012).

18. Sharma, Y. C., Singh, B. \& Upadhyay, S. N. Advancements in development and characterization of biodiesel: A review. Fuel 87, 2355-2373 (2008).

19. Toda, M. et al. Green chemistry: biodiesel made with sugar catalyst. Nature $\mathbf{4 3 8}$ 178-178 (2005).

20. Takagaki, A. et al. Esterification of higher fatty acids by a novel strong solid acid. Catal. Today 116, 157-161 (2006).

21. Mo, X. H., Lotero, E., Lu, C. Q., Liu, Y. J. \& Goodwin, J. G. A novel sulfonated carbon composite solid acid catalyst for biodiesel synthesis. Catal. Lett. 123, 1-6 (2008)

22. Shu, Q., Zhang, Q., Xu, G. H. \& Wang, J. F. Preparation of biodiesel using sMWCNT catalysts and the coupling of reaction and separation. Food. Bioprod. Process. 87, 164-170 (2009).

23. Rao, B. V. S. K., Mouli, K. C., Rambabu, N., Dalai, A. K. \& Prasad, R. B. N. Carbonbased solid acid catalyst from de-oiled canola meal for biodiesel production. Catal. Commun. 14, 20-26 (2011)

24. Yu, H., Jin, Y. G., Li, Z. L., Peng, F. \& Wang, H. J. Synthesis and characterization of sulfonated single-walled carbon nanotubes and their performance as solid acid catalyst. J. Solid. State. Chem. 181, 432-438 (2008).

25. Peng, F., Zhang, L., Wang, H. J., Lv, P. \& Yu, H. Sulfonated carbon nanotubes as a strong protonic acid catalyst. Carbon 43, 2405-2408 (2005).

26. Park, J. Y., Lee, J. S., Wang, Z. M. \& Kim, D. K. Production and characterization of biodiesel from trap grease. Korean J. Chem. Eng. 27, 1791-1795 (2010).

27. Simasatitkul, L., Siricharnsakunchai, P., Patcharavorachot, Y., Assabumrungrat, S. \& Arpornwichanop, A. Reactive distillation for biodiesel production from soybean oil. Korean J. Chem. Eng. 28, 649-655 (2011).
28. Chen, Y. Z., Peng, D. L., Lin, D. X. \& Luo, X. L. Preparation and magnetic properties of nickel nanoparticles via the thermal decomposition of nickel organometallic precursor in alkylamines. Nanotechnology 18, 505703 (2010).

29. Nakamura, T., Ohana, T., Ishihara, M., Hasegawa, M. \& Koga, Y. Chemical modification of single-walled carbon nanotubes with sulfur-containing functionalities. Diam. Relat. Mater. 16, 1091-1094 (2007).

30. Wei, S., Kang, W. P., Davidson, J. L. \& Huang, J. H. Aligned carbon nanotubes fabricated by thermal CVD at atmospheric pressure using Co as catalyst with $\mathrm{NH}_{3}$ as reactive gas. Diam. Relat. Mater. 15, 1828-1833 (2006).

31. Dong, J., Luo, L., Liang, P. H., Dunaway-Mariano, D. \& Carey, P. R. Raman difference spectroscopic studies of dithiobenzoyl substrate and product analogs binding to the enzyme dehalogenase: $\pi$-electron polarization is prevented by the $\mathrm{C}=\mathrm{O}$ to $\mathrm{C}=\mathrm{S}$ substitution. J. Raman Spectrosc. 31, 365-371 (2000).

32. Cech, J. et al. Functionalization of multi-walled carbon nanotubes: Direct proof of sidewall thiolation. Phys. Stat. Sol. (b) 13, 3221-3225 (2006).

33. Tripathy, S. K. \& Yu, Y. T. Spectroscopic investigation of S-Ag interaction in @wmercaptoundecanoic acid capped silver nanoparticles. Spectrochim. Acta Part A 72, 841-845 (2009)

34. Chwaleba, D., II czyszyn, M. M., II czyszyn, M. \& Ciunik, Z. Glycinemethanesulfonic acid $(1: 1)$ and glycine-p-toluenesulfonic acid $(1: 1)$ crystals: comparison of structures, hydrogen bonds, and vibrations. J. Mol. Struct. 831, 119-134 (2007).

35. Hueso, J. L., Espinos, J. P., Caballero, A., Cotrino, J. \& Gonzalez-Elipe, A. R. Carbon 45, 89-96 (2007)

36. Yu, H., Jin, Y. G., Li, Z. L., Peng, F. \& Wang, H. J. Synthesis and characterization of sulfonated single-walled carbon nanotubes and their performance as solid acid catalyst. J. Solid State Chem. 181, 432-438 (2008).

37. Duesberg, G. S. et al. Hydrothermal functionalisation of single-walled carbon nanotubes. Synth. Met. 142, 263-266 (2004).

38. Zheng, S., Kates, M., Dube, M. A. \& McLean, D. D. Acid-catalyzed production of biodiesel from waste frying oil. Biomass Bioenergy 30, 267-272 (2006).

39. Velez, A., Hegel, P., Mabe, G. \& Brignole, E. A. Density and conversion in biodiesel production with supercritical methanol. Ind. Eng. Chem. Res. 49, 7666-7670 (2010).

40. Reddy, C., Reddy, V., Oshel, R. \& Verkade, J. G. Room-temperature conversion of soybean oil and poultry fat to biodiesel catalyzed by nanocrystalline calcium oxides. Energy and Fuels 20, 1310-1314 (2006).

41. Jagadeesh, R. V. et al. Nanoscale $\mathrm{Fe}_{2} \mathrm{O}_{3}$-based catalysts for selective hydrogenation of nitroarenes to anilines. Science 342, 1073 (2013).

42. Westerhaus, F. A. et al. Heterogenized cobalt oxide catalysts for nitroarene reduction by pyrolysis of molecularly defined complexes. Nat. Chem. 5, 537 (2013).

43. Service, R. F. The next big(ger) thing. Science 335, 1167 (2012).

\section{Acknowledgments}

The authors thank the financial supports from the Ministry of Science and Technology of China (2009CB623504), the National Science Foundation of China (20673054, 21273107), and Sinopec Shanghai Research Institute of Petrochemical Technology.

\section{Author contributions}

D.W.P. conceived, designed and directed the study and the analysis and interpretation of results. Z.D.D., W.D.L. and L.Q. performed catalyst synthesis, characterization and testing. G.X. and G.X.F. participated in data analysis and simulation. X.Z.K. collaborated in mathematic modeling. The manuscript was co-written by D.W.P., Z.D.D. and W.D.L.

\section{Additional information}

Supplementary information accompanies this paper at http://www.nature.com/ scientificreports

Competing financial interests: The authors declare no competing financial interests.

How to cite this article: Zhang, D.D. et al. High performance catalytic distillation using CNTs-based holistic catalyst for production of high quality biodiesel. Sci. Rep. 4, 4021; DOI:10.1038/srep04021 (2014).

This work is licensed under a Creative Commons AttributionNonCommercial-NoDerivs 3.0 Unported license. To view a copy of this license, visit http://creativecommons.org/licenses/by-nc-nd/3.0 